\title{
Religious Activity and Risk Behavior Among African American Adolescents: Concurrent and Developmental Effects
}

\author{
Kenneth J. Steinman ${ }^{1,3}$ and Marc A. Zimmerman ${ }^{2}$
}

This study examines how religious activity is associated with risk behaviors, concurrently and developmentally among urban African American adolescents. Seven hundred and five African American youths were interviewed annually during high school. Retention rates for the study exceeded $90 \%$. Frequency of religious activity, sexual intercourse, and alcohol, cigarette, and marijuana use were assessed at each wave. Growth curve analyses found negative concurrent associations between religious activity and each of the four risk behaviors. The developmental effects of religious activity varied by gender. Higher levels of religious activity in 9th grade predicted smaller increases in marijuana use among males and cigarette use among females. In addition, larger decreases in religious activity during high school were associated with greater increases in alcohol use among males and sexual intercourse among females. During high school, religious activity limits the development of certain types of risk behavior among African American youth, even after controlling for reciprocal effects.

KEY WORDS: adolescent development; African Americans; gender differences; religion; sexual intercourse; substance use.

\section{INTRODUCTION}

Investigators have long recognized that religious activity may inhibit adolescent risk behavior. Previous research suggests that youth who regularly participate in religious activities are less likely to use alcohol and other drugs or to engage in sexual intercourse (Donahue, 1995; Wallace \& Forman, 1998). Though the magnitude of these associations is sometimes modest, the great prevalence of religious activity among American youth warrants its study as a potential protective factor (Wallace \& Williams, 1997).

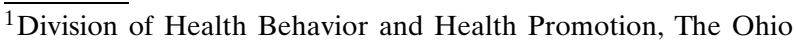
State University School of Public Health, Columbus, Ohio.

${ }^{2}$ Department of Health Behavior and Health Education, University of Michigan School of Public Health, Ann Arbor, Michigan.

${ }^{3}$ To whom correspondence should be addressed at Division of Health Behavior and Health Promotion, The Ohio State University School of Public Health, B-215 Starling-Loving Hall, 320 West 10th Avenue, Columbus, Ohio 43210-1240; e-mail: steinman.13@osu.edu.
}

Researchers have suggested that religious activity may influence risk behavior through a variety of mechanisms such as internalizing beliefs about the immorality of risk behaviors (Burkett, 1977; Francis, 1997; Lorch \& Hughes, 1985), influencing peer group affiliation (Burkett \& Warren, 1987), improving family relationships (Bahr, Maughan, Marco, \& Li, 1998; Brody, Stoneman \& Flor, 1996), and involvement in prosocial activities (Benson, 1992; Buckhalt, Halpin, Noel, \& Meadows, 1992; Zimmerman \& Maton, 1992). Much of what we know about religious activity and adolescent risk behavior, however, is based on cross-sectional research (Koenig, McCullough, \& Larson, 2001). Although many studies have examined potential mediating mechanisms, few researchers have considered whether religious activity limits the development of risk behaviors over time. Such research is critical to determine the temporal ordering of these effects as well as how they operate developmentally (cf. Burkett \& Warren, 1987; Mason \& Windle, 2002). 
If little is known about the developmental effects of religious activity on adolescent risk behavior, even less is known about how such processes may operate among young African Americans. Numerous authors have argued that religion may be particularly important for healthy development among African American youths (Christian \& Barbarin, 2001; Johnson, Larson, De Li, \& Jang, 2000; Lincoln \& Mamiya, 1990; Winfield, 1995). Several studies, however, suggest that the effect of religiosity on risk behavior among African Americans is similar to (Donahue, 1995; Wallace \& Forman, 1998) or smaller than (Amey, Albrecht, \& Miller, 1996; Steinman \& Sahr, 2002) its effect among other youth. Given this discrepancy, there exists a need to clarify how religiosity may influence different risk behaviors in this population.

The purpose of this study is to examine how religious activity may operate concurrently and developmentally as a protective factor among African American youth. The outcomes that are the focus of this study include common types of risk behaviors: sexual intercourse and the use of alcohol, cigarettes, and marijuana. Because the effects of religious activity may vary across different adolescent risk behaviors, we analyzed separate models for each of these behaviors (Hadaway, Elifson, \& Peterson, 1984; Wallace \& Forman, 1998).

Religious activity and risk behavior can change markedly during adolescence, and assessing even the bivariate relationship between these variables over time can be very complex. Given the paucity of longitudinal research in this area, we chose to focus on describing the form of the religiosity-risk connection during adolescence. Future studies with this data (currently in preparation by the authors) will test how other risk and protective factors may explain the influence of religiosity on the development of risk behavior.

\section{Religious Activity and Risk Among African American Youth}

Previous studies of African American adolescents have found a negative association between religiosity and a variety of risk behaviors, including sexual behavior (Brown, 1985), alcohol abuse (Barnes, Farrell, \& Banerjee, 1994), and smoking marijuana or cigarettes (Amey et al., 1996). On closer examination, however, the religion-risk connection appears more complex. Compared with their peers, African
American teens are more likely to attend religious services (Donahue, 1995) and, perhaps not surprisingly, are less likely to smoke cigarettes or drink alcohol (Johnston, O'Malley, \& Bachman, 2001). Yet, young African Americans also engage in sexual intercourse and smoke marijuana as often or more often than other youth (Johnston et al., 2001; Centers for Disease Control and Prevention, 2000). Such findings suggest that African American teens' higher levels of religious activity may help explain ethnic group differences in the prevalence of some risk behaviors but not others (Amey et al., 1996; Christian \& Barbarin, 2001). Consistent with this, one hypothesis for this study is that religious activity will limit the development of alcohol and cigarette use but not marijuana and sexual intercourse in this population.

Other evidence, however, suggests an alternative hypothesis: that religious activity will have the greatest influence on those risk behaviors most explicitly proscribed by religious denominations common to African Americans (e.g., Baptist). Many denominations sanction premarital sexual behavior and alcohol use more strongly than smoking cigarettes or marijuana (Bock, Cochran, \& Beeghley, 1987). From this perspective, a competing hypothesis is that religious activity will be more strongly associated with alcohol use and sexual behavior than cigarette or marijuana use.

Just as patterns of religious activity may influence risk behavior, it is also possible that risk behaviors may affect subsequent changes in religious activity (Burkett \& Warren, 1987). In a sample of high school students, Mason and Windle (2002) found that religious attendance at Time 1 predicted alcohol use at Time 2 and that alcohol use at Time 1 predicted religious attendance at Time 2 . Thus, to estimate the influence of religious activity on adolescent risk behavior it is important to first control for the possibility of such reciprocal influences.

\section{Gender Differences}

Previous findings point to important gender differences in religious activity and its influence on adolescent risk behavior. Female teens attend religious services more often than males (Donahue, 1995) and report lower rates of sexual intercourse, as well as alcohol and marijuana use (Johnston et al., 2001). In addition, the association between religious activity and adolescent risk behavior may vary by gender. Using a nationally representative sample, Rosenbaum and 
Kandel (1990) reported that church attendance curtailed intercourse before age 16 , but the effect was stronger for females than males.

Few investigators, however, have studied gender differences in the association between religious activity and risk behavior specifically among African American youths. This gap in the literature may be significant, as many African American churches have different expectations for young men and women, expectations that may influence gender differences risk behavior (Lincoln \& Mamiya, 1990). In the words of one young man, "[It's] time to be a man and learn the ways of the world. Leave the church to the women" (Lincoln \& Mamiya, 1990, p. 305).

\section{Religious Attendance as an Indicator of Religiosity}

Frequency of attending religious services is perhaps the most widely used indicator of religiosity. Although it represents only one of several dimensions of religiosity among youth (Holder et al., 2000), religious attendance is an essential part of most conceptual definitions of religiosity. Among studies that do examine several dimensions of religion (e.g., religious beliefs, importance, affiliation), attendance often exhibits the strongest associations with adolescent risk behaviors (cf. Lorch \& Hughes, 1985; Mullen \& Francis, 1995). In longitudinal studies, attendance is often the only dimension of religiosity associated with changes in risk behavior over time (cf. Evans, Cullen, Dunaway, \& Burton, 1995; Mason \& Windle, 2002).

Measures of religious attendance, however, do not only assess attending religious services per se. Rather, study participants often include a broader range of participation in religious activities (e.g., church suppers, bible study, youth rallies) in response to such questions (Freeman, 1986). In this study, we label such behavior "religious activity" and define it as youths' overall involvement in organized religious activities.

Although the studies cited above were based on different population groups, we recognize that the nature and effects of religiosity among African Americans may be unique and, therefore, merit a distinct conceptual framework (Myers, 1993). Mattis and Jagers (2001) have proposed one such a framework that highlights the process of religious/spiritual socialization across (i.e., parents, extended family members) and within (i.e., peers) generations. In this light, the findings from this study may only be relevant to African American youths.
In summary, the purpose of the study is to examine how religious activity is associated with different risk behaviors, concurrently and developmentally among urban African American adolescents and to test whether these relationships differ for males and females.

\section{METHODS}

\section{Sample}

The sample consisted of 705 African American high school students from four public high schools in a midsized city in the Midwest. Approximately half of the students in the study were female $(n=360)$ and half were male $(n=345)$. These data were collected as part of a larger study of students at risk for leaving school before graduation: participating students all had grade point averages of 3.0 or lower and were not listed as developmentally disabled in school records. Trained interviewers administered a structured one-on-one interview with each student in school (students who had left school were interviewed at other locations). Data were collected annually beginning in 1994 when participants were in 9th grade and continued through 12 th grade. Sample retention rates at each wave of the study exceeded $95 \%$ and were $90 \%$ from Year 1 to 4 . To address biases potentially introduced by sample attrition, parallel analyses were performed, one with complete cases only and another with a data set that imputed values for missing data based on the EM algorithm. The study presents results from the analyses on the imputed data set. The University of Michigan Institutional Review Board approved the protocol for the study.

\section{Measures}

Religious activity was assessed by a single item, "How often do you attend church or other religious services?" The original seven response options were collapsed into five categories: not at all (0), a few times per year (1), once or twice per month (2), once per week (3), and more than weekly (4).

Frequencies of alcohol and marijuana use each were assessed by multiplying a frequency measure of use during the previous year with a frequency measure of use during the previous month. The resulting measures each included a possible range of 0-49.

A single item assessed typical amount of cigarette use during the past month. The seven response 


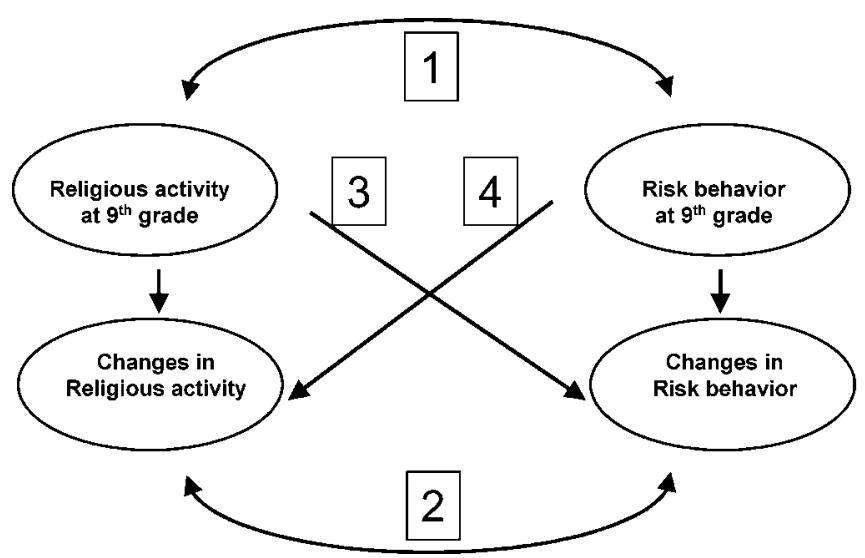

Fig. 1. Parameters estimated for growth curve models of religious activity and each of four risk behaviors (i.e., alcohol use, cigarette use, marijuana use, sexual intercourse). Key: $1=$ How religious activity and risk behavior are associated concurrently in ninth grade $2=$ How changes in religious activity during high school are accompanied by changes in risk behavior; $3=$ How religious activity at ninth grade affects later changes in risk behavior; $4=$ How risk behavior at ninth grade affects later changes in religious activity.

options ranging from none (0) to two packs a day or more (6) were recoded to represent the corresponding number of cigarettes and yield a more interpretable metric. The possible range of the measure extended from 0 to 40 .

Frequency of sexual intercourse during the past month was based on a single item. Responses ranged from not in the last month (1) to 12 or more times (5). Respondents who had previously indicated on the survey that they had never had sexual intercourse skipped this item but had their responses recoded from missing to never (0).

\section{Data Analysis}

Analyses were based on a series of growth curve models (Willett \& Sayer, 1994; Curran, 2000). Growth curve modeling is a powerful technique for assessing change that occurs within individuals over time. The procedure views changes within individuals as a function of two latent factors: an intercept and a slope. Each participant's growth trajectory is viewed as variation around the sample estimates of these unobserved factors. An investigator aims to identify the measurement model for a variable; that is, the functional form that accurately and concisely summarizes how the population changes over time.

Once the measurement models are identified, parallel process models estimate how individual variation in the slope and intercept of different variables (e.g., religious activity and alcohol use) relate to one another. The present study used such parallel process models to estimate four parameters (see Fig. 1): First is the association between the religious activity and risk behavior intercepts (parameter \#1). Conceptually, this parameter represents the concurrent association between religious activity and the risk behavior at ninth grade. A second parameter involves the association between the religious activity and risk behavior slopes (parameter \#2). This parameter tests whether changes in religious activity during high school are accompanied by changes in risk behavior. The third type of parameter is the effect of the religious activity intercept on the risk behavior slope (parameter \#3). That is, whether religious activity in ninth grade influences the later development of risk behavior. Finally, the fourth parameter measures the effect of the risk behavior intercept on the religious activity slope (parameter \#4). This represents the influence of risk behavior at ninth grade on later changes in religious activity. By including it in the model we can control for such reciprocal influences when estimating the other effects. Testing for gender differences involved multigroup analyses with Lagrangian Multiplier Tests that helped assess whether and how the growth models differed by gender.

\section{RESULTS}

This section first presents results that describe how religious activity and the four risk behaviors changed during the study, and whether these changes 
Table I. Means and Standard Deviations for Study Variables at Each Wave, $n=705$

\begin{tabular}{lccccc}
\hline & 9th Grade & 10th Grade & 11th Grade & 12th Grade & Range \\
\hline Religious activity $^{2.44(1.30)}$ & $2.24(1.33)$ & $2.25(1.28)$ & $2.16(1.27)$ & $0-4$ \\
Alcohol use $^{a}$ & $0.34(0.46)$ & $0.43(0.48)$ & $0.45(0.50)$ & $0.52(0.47)$ & $0-1.70$ \\
Marijuana use $^{a}$ & $0.31(0.50)$ & $0.50(0.59)$ & $0.49(0.59)$ & $0.53(0.59)$ & $0-1.70$ \\
Cigarette use $^{a}$ & $0.12(0.26)$ & $0.15(0.31)$ & $0.20(0.35)$ & $0.25(0.40)$ & $0-1.61$ \\
Sexual intercourse & $1.89(1.81)$ & $2.13(1.79)$ & $2.46(1.86)$ & $2.84(1.90)$ & $0-5$ \\
\hline${ }^{a}$ Log transformed. & & & & &
\end{tabular}

differed for males and females. Next, we present results that describe how changes in religious activity were associated with changes in each of the four risk behaviors.

Descriptive statistics for the study variables appear in Table I. As with many studies of adolescent risk behavior, several of the variables in the study had nonnormal distributions. Of particular concern to growth curve modeling is multivariate kurtosis, which may lead investigators to inappropriately reject true models as well as underestimate the standard errors of effect sizes (Curran, 2000). To address this concern it was necessary to transform the alcohol, cigarette, and marijuana use variables using a log transformation. This markedly reduced multivariate kurtosis in each of the models.

\section{Measurement Models}

The first series of analyses identified the measurement models that accurately and concisely described changes in religious activity, alcohol use, cigarette use, marijuana use, and sexual intercourse.

\section{Religious Activity}

Religious activity decreased during the 4 years of the study (slope $=-0.086, S E=147, p<.01$ ) and a linear function described this change reasonably well $\left(\chi^{2}(5)=15.232, p<.01, \mathrm{RMSEA}=0.054\right)$. Allowing the 10th grade wave to vary freely (i.e., rather than be fixed to the linear trend) improved model fit $\left(\chi^{2}\right.$ difference $(2)=5.634), p<.01)$. This revised model was selected as the measurement model of religious activity.

\section{Alcohol Use}

Alcohol use increased during the study (slope $=$ $0.046, S E=.009, p<.01)$ but a simple linear function did not model this change very well $\left(\chi^{2}(5)=28.547\right.$, $p<.01$, RMSEA $=0.082)$. Allowing the ninth grade wave to vary, however, yielded a model that fit the data well $\left(\chi^{2}(3)=8.031, p=.04\right.$, RMSEA $\left.=0.049\right)$.

\section{Cigarette Use}

Cigarette use also increased during the study (slope $=0.045, S E=.005, p<.01$ ) and a linear function adequately modeled this change $\left(\chi^{2}(5)=18.475\right.$, $p<.01$, RMSEA $=0.062$ ). Freeing individual waves did not improve model fit and a quadratic term, when added to the model, was not significant.

\section{Marijuana Use}

Marijuana use increased during the study (slope $=0.063, S E=.007, p<.01$ ), but this growth could not be characterized as linear $\left(\chi^{2}(5)=85.645\right.$, $p<.01$, RMSEA $=0.151$ ). Model fit improved, however, after revising the model to allow the ninth grade wave to vary freely $\left(\chi^{2}(3)=7.741, p=.05\right.$, RMSEA $=0.047$ ).

\section{Sexual Intercourse}

The frequency of sexual intercourse increased during the study (slope $=0.318, S E=.025, p<.01$ ), and this growth could be described reasonably well by a simple linear function $\left(\chi^{2}(5)=16.147, p=.05\right.$, RMSEA $=0.056)$. Neither freeing individual waves nor adding a quadratic term improved the model fit.

\section{Gender Differences in Measurement Models}

Multigroup analyses detected several gender differences in how the study variables changed over time. These differences are illustrated in Fig. 2, where mean scores at each wave are plotted separately for males and females.

The measurement model describing changes in religious activity was similar for males and females, except that the intercept was higher among females 

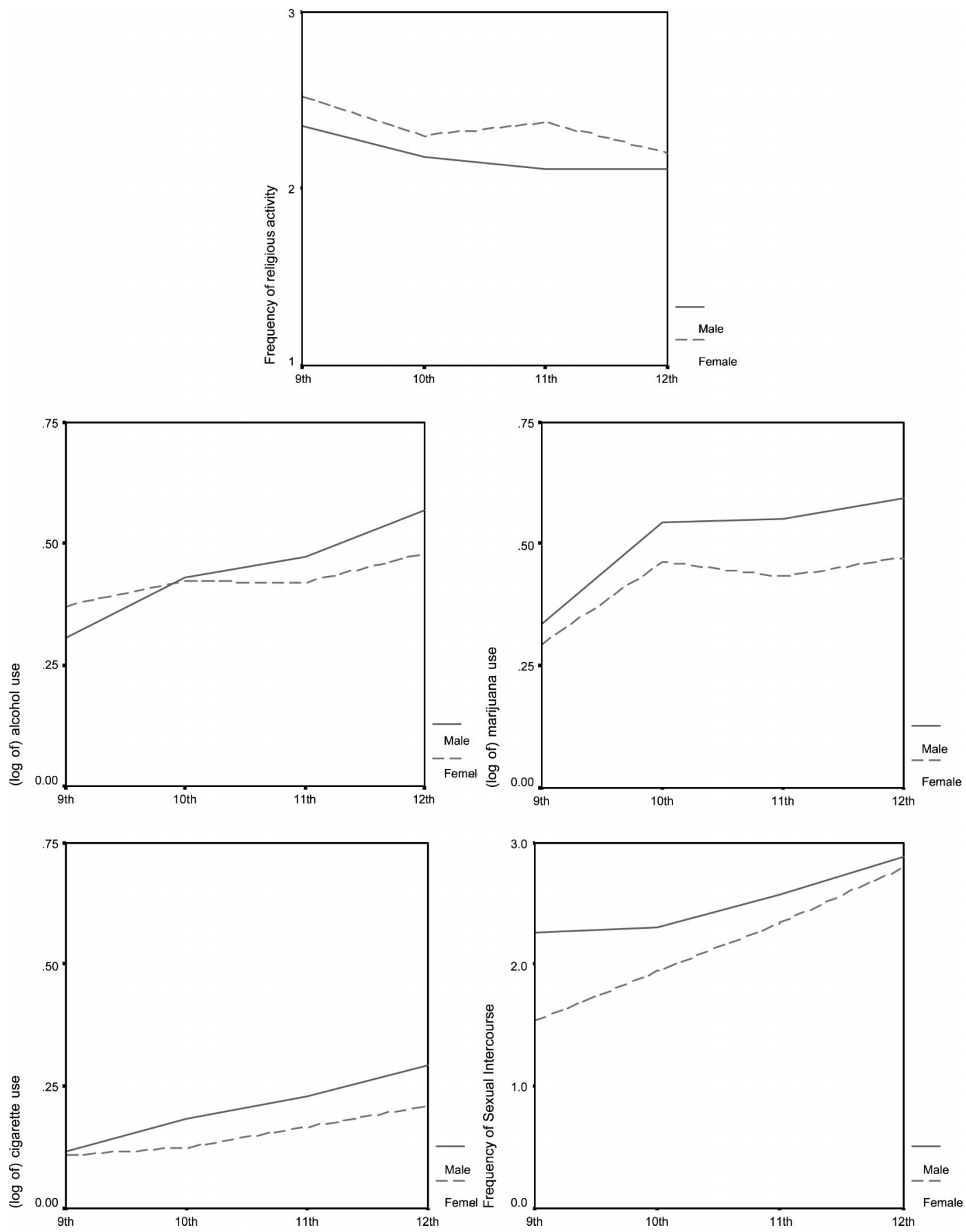

Fig. 2. Mean values of religious activity, alcohol use, cigarette use, marijuana use, and sexual intercourse: 9th-12th grade (males $n=345$; females $n=360$ ).

$\left(\chi^{2}(1)=4.060, p=.04\right)$. The measurement models of marijuana use were also similar except that the intercept for males was higher $\left(\chi^{2}(1)=6.565, p=.01\right)$. For alcohol use, the slope was larger for males and value of the freely varying wave differed by gender $\left(\chi^{2}(2)=\right.$
$22.234, p<.01)$. The slope of cigarette use was greater for males than females $\left(\chi^{2}(1)=8.578, p<.01\right)$, while the slope of sexual intercourse was greater among females and the intercept was higher for males $\left(\chi^{2}(2)=\right.$ 28.239, $p<.01)$. 
Table II. Association Between Religious Activity and Risk Behaviors: Effect Sizes and Standard Errors

\begin{tabular}{lcccc}
\hline & $\begin{array}{c}\text { Covariance of } \\
\text { religious activity } \\
\text { and risk behavior } \\
\text { intercepts }\end{array}$ & $\begin{array}{c}\text { Covariance of } \\
\text { religious activity } \\
\text { and risk behavior } \\
\text { slopes }\end{array}$ & $\begin{array}{c}\text { Effect of } \\
\text { religious activity } \\
\text { intercept on risk } \\
\text { behavior slope }\end{array}$ & $\begin{array}{c}\text { Effect of risk } \\
\text { behavior intercept } \\
\text { on religious } \\
\text { activity slope }\end{array}$ \\
\hline $\begin{array}{l}\text { Males }(n=345) \\
\text { Alcohol use }\end{array}$ & $-.129(.027)^{* *}$ & $-.006(.003)^{*}$ & $.000(.010)$ & $.210(.112)$ \\
Cigarette use & $-.108(.019)^{* *}$ & $-.004(.003)$ & $.008(.011)$ & $.408(.162)^{* *}$ \\
Marijuana use & $-.241(.052)^{* *}$ & $.001(.004)$ & $-.060(.015)^{* *}$ & $-.006(.041)$ \\
Sexual intercourse & $-.725(.125)^{* *}$ & $-.005(.011)$ & $-.011(.046)$ & $-.010(.020)$ \\
Females $(n=360)$ & $-.148(.030)^{* *}$ & $-.002(.003)$ & $.007(.010)$ & $.103(.089)$ \\
Alcohol use & $-.044(.022)^{*}$ & $-.001(.003)$ & $-.025(.008)^{* *}$ & $-.012(.086)$ \\
Cigarette use & $-.156(.030)^{* *}$ & $-.002(.004)$ & $.037(.108)$ & $.004(.104)$ \\
Marijuana use & $-.367(.109)^{* *}$ & $-.029(.012)^{* *}$ & $.001(.039)$ & $.014(.019)$ \\
Sexual intercourse & & & & \\
\hline Note. Alcohol use, cigarette use, and marijuana use were transformed using a log transformation. \\
$* p<.05$.
\end{tabular}

\section{Religious Activity and Risk Behaviors: Parallel Process Models}

Because the measurement models differed for males and females, it was not appropriate to test for gender differences in the parallel process models. Instead, we estimated separate models by gender. Table 2 presents the unstandardized coefficients of concurrent and prospective effects between religious activity and each of the four risk behaviors.

\section{Alcohol Use}

For both genders, religious activity had a strong negative concurrent association with alcohol use (males: $\operatorname{cov}=-.129, S E=.027, p<.01$; females: $\operatorname{cov}=-.148, S E=.030, p<.01)$. In addition, ninth grade alcohol use did not influence the development of religious activity for either gender. Among males only, analyses detected a negative association between changes in religious activity and changes in alcohol use (cov $=-.006, S E=.003, p<.05)$. In other words, greater than average decreases in religious activity during high school were associated with greater than average increases in alcohol use. Model fit for males $\left(\chi^{2}(20)=35.35, p=.02\right.$, RMSEA $\left.=0.047\right)$ and females $\left(\chi^{2}(20)=26.52, p=.15\right.$, RMSEA $\left.=0.030\right)$ was acceptable.

\section{Cigarette Use}

The negative concurrent association between religious activity and cigarette use was stronger for males than for females. For females but not males, ninth grade religious activity suppressed increases in cigarette use during high school $(\gamma=-.025, S E=$ $.008, p<.01)$. Conversely, cigarette use in ninth grade was associated with smaller than average decreases in religious activity among males $(\gamma=.408, S E=$ $.162, p<.01)$ but not females $(\gamma=-.012, S E=.086$, $p=.88)$. Changes in religious activity were not associated with changes in cigarette use among males or females. Model fit was acceptable for both males $\left(\chi^{2}(22)=37.82, p=.02\right.$, RMSEA $\left.=0.046\right)$ and females $\left(\chi^{2}(18)=22.96, p=.19\right.$, RMSEA $\left.=0.028\right)$.

\section{Marijuana Use}

For both males and females, the concurrent association of religious activity and marijuana use was negative, and reciprocal effects (i.e., the effect of ninth grade marijuana use on changes in religious activity) were not detected. For males, religious activity in ninth grade limited subsequent increases in marijuana use $(\gamma=-.060, S E=.015, p<.01)$, but there was no association between the slopes of the two variables. Among females, neither the initial level of, nor changes in religious activity influenced changes in marijuana use. The model fit the data well for both males $\left(\chi^{2}(20)=34.38, p=.02\right.$, RMSEA $\left.=0.046\right)$ and females $\left(\chi^{2}(18)=11.58, p=.86\right.$, RMSEA $\left.=0.000\right)$.

\section{Sexual Intercourse}

A strong negative concurrent association between religious activity and sexual intercourse was 
detected. For both genders, the initial level of religious activity was not found to influence changes in sexual intercourse. No reciprocal effects were detected for either gender. Among females only, we found a negative association between changes in religious activity and changes in sexual intercourse ( $\operatorname{cov}=-.029, S E=$ $.012, p<.01)$. That is, greater than average decreases in religious activity during high school were associated with greater than average increases in the frequency of sexual intercourse. Model fit was very good for both males $\left(\chi^{2}(20)=26.73, p=.14\right.$, RMSEA $\left.=0.031\right)$ and females $\left(\chi^{2}(20)=28.99, p=.09\right.$, RMSEA $=$ $0.035)$.

\section{Results Based on Listwise Deletion}

To address the potential bias introduced by missing data, we conducted parallel analyses with individuals who were present during all four waves of the study. Across the four risk behaviors, the sample sizes for males ranged from 224 to 247. For females, sample sizes ranged from 274 to 290 .

The results of the analyses (available from the authors) were very similar to those produced using imputed values for missing data with two exceptions: In analyses using listwise deletion, the effect of ninth grade religious activity on changes in cigarette use was not significant for females $(\gamma=-.002, S E=.003$, $p=.72$ ). Also, changes in religious activity were not associated with changes in sexual intercourse among females $(\operatorname{cov}=-.013, S E=.014, p=.48)$.

\section{DISCUSSION}

Consistent with previous research, the findings of this study suggest that when African American youths are more religiously active they tend to be less involved in sexual intercourse as well as alcohol, cigarette, and marijuana use (Amey et al., 1996; Barnes et al., 1994; Freeman, 1986; Johnson et al., 2000; Murray, 1994; Wallace \& Forman, 1998). These findings correspond to parameter \#1 (see Fig. 1) but offers little insight about how religious activity is associated with changes in risk behaviors over time. We considered two types of developmental protective effects of religious activity: whether changes in religious activity were accompanied by changes in risk behaviors (parameter \#2), and whether the level of religious activity in ninth grade influenced later changes in risk behaviors (parameter \#3).

\section{Changes in Religious Activity Affect Changes in Risk Behavior}

Declining religious activity was associated with larger increases in alcohol use among males and, perhaps, sexual behavior among females. Diminished interest in religious activity is common during adolescence and may reflect youths' emerging autonomy and an identity that is independent of a family focus on religion (Erikson, 1968). Burkett (1977) found a strong positive relationship between parents' religious attendance and their children's alcohol and marijuana use among youths who did not themselves attend church. He attributed this finding to teens' alienation and withdrawal from parental influence.

One potential novel finding of this study is that expressions of autonomy may vary by gender, as females are more likely to turn to sexual activity and males to alcohol. This offers some support for the second study hypothesis that religious activity will influence those risk behaviors that are most emphatically proscribed by denominations common to African Americans (Bock et al., 1987). Youths may be more likely to internalize values that view alcohol use or premarital sex as immoral because they are most strongly condemned by religious doctrine (Burkett, 1977; Francis, 1997; Lorch \& Hughes, 1985).

It is unclear, however, why these effects were not detected for both genders. Part of the answer may be statistical, as females in the study increased their alcohol use very little during high school (see Fig. 2), so there were few changes for church attendance to influence. Among males, the absence of effects on sexual intercourse may indicate that religious activity only influences young men's sexual behavior when accompanied by other dimensions of religiosity. It is possible that some young men are religiously active, but do not subscribe to religious proscriptions against sexual behavior. Jensen and colleagues (1990), for instance, reported that the influence of church attendance on sexual behavior was much greater among males who had nonpermissive attitudes regarding premarital sex. In contrast, the effect of church attendance on sexual behavior among females did not depend on permissiveness.

\section{Religious Activity in Ninth Grade Affects Later Changes in Risk Behavior}

Parameter \#3 in Fig. 1 represents the enduring influence of religious activity. The more African 
American males attended church in ninth grade the less they increased their marijuana use throughout high school. Among females, religious activity at ninth grade limited subsequent increases in cigarette use.

One interpretation of these findings involves peer group influences, which are central to adolescent smoking and drug use (Petraitis, Flay, \& Miller, 1995). Though peer socialization may influence young people to increase such behavior, it is also true that youth tend to affiliate with similar others. Thus, youths often form homophilic peer groups based on psychosocial factors that are related to substance use (Burkett \& Warren, 1987; Engels, Knibbe, Drop, \& Dehaan, 1997; Fisher \& Bauman, 1988). Because patterns of religious involvement carry over from childhood (Donahue, 1995), religiously active youth who enter high school may be more likely to form friendships with other prosocial teens who are less predisposed to substance use. Even if their religious activity declines, membership in such peer groups may continue to limit their use of cigarettes or marijuana. Youniss, Yates, and Su (1997), for example, found that peer groups with an orientation to academic, religious, and other adult institutions used less marijuana than those oriented towards peer fun.

In proposing this explanation it is also necessary to consider why similar effects were not found for alcohol use. After all, like cigarettes and marijuana, alcohol is typically consumed as a social activity among adolescents (Mayer, Forster, Murray, \& Wagenaar, 1998). The statistical artifact noted earlier may explain the absence of such findings among females. For males, the influence of religious activity on alcohol use may not be enduring as it is for marijuana use. Rather, curtailing alcohol use may depend on remaining religiously active, perhaps an indication of one's continuing acceptance of a religious identity. Joining a prosocial peer group, for instance, may not protect male youth from experimenting with alcohol; in the same way it will discourage their progressing to marijuana use.

\section{Reciprocal Influences of Risk Behaviors on Religious Activity}

We detected little evidence of the reciprocal influence of risk behaviors on subsequent changes in religious activity. Only cigarette use among males predicted smaller decreases in religious activity during high school. If smoking enjoins fewer religious proscriptions than other types of substance use or sexual activity, then youths who smoke may experience less difficulty reconciling their risk behavior with their religious identity. Still this explanation only explains why cigarette use might not be associated with changes in religious activity. It remains unclear why young males who smoke were actually less likely to decrease their religious activity during high school.

The reciprocal effects of risk behavior on religious activity have been reported previously. In a recent study of high school youth, Mason and Windle (2002) found that alcohol use had a negative effect on religious activity measured 1 year later. Because these effects were estimated in separate regression equations, however, it was not possible to establish which of these effects predominated. By incorporating both effects in the same model, we were able to determine that overall, the influence of religious activity on risk behaviors appears to be greater than most reciprocal effects.

\section{Implications for Prevention}

Many congregations include programming that aims to keep teenagers connected with religious institutions and away from risk behaviors. In African American churches in particular, these efforts often extend beyond members of the congregation to the surrounding community (Thomas, Quinn, Billingsley, \& Caldwell, 1994). The results of this study suggest that some of these efforts may be promising, but that the results could vary markedly for males and females.

Programming that is limited to ninth grade may have lasting effects on marijuana use among males and cigarette use among females but could be less effective at curtailing other risk behaviors. For instance, many African American churches develop programming to influence teens' sexual behavior (CoyneBeasley \& Schoenbach, 2000). Such programming should remain realistic, relevant, and engage young people throughout their high school years to be effective. At the same time, practitioners should be aware of the potential harm associated with simply encouraging religious activity as a means to limit sexual behavior. Studer and Thornton (1987) found that religious activity protected against sexual intercourse among females, but also reduced contraceptive use among those who were sexually active.

Our findings also support the potential protective effects of prosocial behavior. Young people who are religiously active also tend to participate in extracurricular activities and community service (Donahue, 
1995). As such, religious activity may be better viewed as one indicator of a broader orientation involving conventional values and behaviors (cf. Youniss, McLellan, Su, \& Yates, 1999). In many African American communities, young people who feel little connection to schools, clubs, or other social institutions may still be willing to affiliate with a church. Practitioners may wish to facilitate this process, for even in the absence of other social connections, religious affiliation may curtail teens' risk behavior (Zimmerman \& Maton, 1992).

\section{Study Strengths and Limitations}

Having a sufficiently large data set with relatively low attrition was a major strength of the study. This was demonstrated in the overall consistency of findings between the data sets that either imputed or deleted cases with missing data. A few discrepancies do raise some doubts about the protective effects of religious activity among females, though we remain confident in our findings for males. Future studies in this area should examine whether findings vary by gender.

A limitation of the study is that the data depended on self-report measures. Young people often are unwilling to report risk behaviors, and such underreporting may be especially common among African Americans (Fendrich \& Vaughn, 1994). The study results therefore may be a conservative estimate of the actual relationship between religious activity and risk behavior. Nonetheless, the effects we did find were robust enough to be detected with limited variance, i.e., underreporting bias. Of related concern was that we relied on single item measures of key variables (i.e., religious activity, cigarette use, sexual intercourse). Some evidence suggests single item measures of religiosity can capture a broad range of religious activity (see Gorsuch \& McFarland, 1972), but the complexity of African American spirituality and religiosity will require much more sophisticated conceptual and operational approaches to measurement.

A second concern is that the study did not begin earlier than ninth grade, when family patterns of religious activity are established and before the advent of most risk behaviors. To understand prospective influences of religious activity on risk behaviors, it would be preferable to begin interviewing students at an earlier age. Nevertheless, the analytic approach did help isolate how religious activity influences the development of risk behaviors in this population.

\section{CONCLUSIONS}

Our findings suggest that religious activity can influence the development of certain risk behaviors among African American youths during high school. Though our findings are based on only one sample, the measures we used can be found in many prospective cohort studies and will make it relatively easy to replicate this study. As we begin to understand the longitudinal associations of religious activity and risk behaviors, another direction for future research will involve testing different mechanisms that may best explain this relationship. Family relationships (Bahr et al., 1998; Brody et al., 1996), peer group affiliations (Burkett \& Warren, 1987), and social bonding (Benson, 1992; Youniss et al., 1997) appear especially promising in this regard. Such research will help us understand the development of prosocial and risk behavior during adolescence and identify the limits and potential role of faith-based organizations in adolescent health promotion.

\section{ACKNOWLEDGMENTS}

This research was funded by the National Institute on Drug Abuse, Grant No. DA07484. The views or policies expressed do not necessarily reflect the views or policies of the National Institute on Drug Abuse.

\section{REFERENCES}

Amey, C. H., Albrecht, S. L., \& Miller, M. K. (1996). Racial differences in adolescent drug use: The impact of religion. Substance Use and Misuse, 31(10), 1311-1332.

Bahr, S. J., Maughan, S. L., Marcos, A. C., \& Li, B. (1998). Family, religiosity, and the risk of adolescent drug use. Journal of Marriage and the Family, 60, 979-992.

Barnes, G. M., Farrell, M. P., \& Banerjee, S. (1994). Family influences on alcohol abuse and other problem behaviors among Black and White adolescents in a general population sample. Journal of Research on Adolescence, 4(2), 183-201.

Benson, P. L. (1992). Religion and substance use. In J. F. E. Schumaker (Ed.), Religion and mental health (pp. 211-220). New York: Oxford University Press.

Bock, E. W., Cochran, J. K., \& Beeghley, L. (1987). Moral messages: The relative influence of denomination on the religiosityalcohol relationship. Sociological Quarterly, 28(1), 89-103.

Brody, G. H., Stoneman, Z., \& Flor, D. (1996). Parental religiosity, family processes, and youth competence in rural two-parent African American families. Developmental Psychology, 32, 696-706.

Brown, S. V. (1985). Premarital sexual permissiveness among black adolescent females. Social Psychology Quarterly, 48, 381-387.

Buckhalt, J. A., Halpin, G., Noel, R., \& Meadows, M. E. (1992). Relationship of drug use to involvement in school, home, and community activities: Results of a large survey of adolescents. Psychological Reports, 70(1), 139-146. 
Burkett, S. R. (1977). Religion, parental influence, and adolescent alcohol and marijuana use. Journal of Drug Issues, 7(3), 263273.

Burkett, S. R., \& Warren, B. O. (1987). Religiosity, peer associations and adolescent marijuana use: A panel study of underlying causal structures. Criminology, 25(1), 109-131.

Christian, M. D., \& Barbarin, O. A. (2001). Cultural resources and psychological adjustment of African American children: Effects of spirituality and racial attribution. Journal of Black Psychology, 27(1), 43-63.

Coyne-Beasley, T., \& Schoenbach, V. J. (2000). The African American church: A potential forum for adolescent comprehensive sexuality education. Journal of Adolescent Health, 26(4), 289-294.

Curran, P. J. (2000). A latent curve framework for the study of developmental trajectories of substance use. In J. S. Rose, L. Chassin, C. C. Presson, \& S. J. Sherman (Eds.), Multivariate applications in substance use research: New methods for new questions (pp. 1-42). Mahwah, NJ: Erlbaum.

Donahue, M. J. (1995). Religion and the well-being of adolescents. Journal of Social Issues, 51(2), 145-160.

Engels, R. C. M. E., Knibbe, R. A., Drop, M. J., \& de Haan, Y. T. (1997). Homogeneity of cigarette smoking within peer groups: Influence of selection? Health Education \& Behavior, 24, 801811.

Erikson, E. (1968). Identity: Youth and crisis. New York: Norton.

Evans, T. D., Cullen, F. T., Dunaway, R. G., \& Burton, V. S. (1995). Religion and crime re-examined: The impact of religion, secular controls and social ecology on adult criminality. Criminology, 33, 195-217.

Fendrich, M., \& Vaughn, C. (1994). Diminished lifetime substance use over time: A validated inquiry into differential underreporting. Public Opinion Quarterly, 58(1), 96-123.

Fisher, L. A., \& Bauman, K. E. (1988). Influence and selection in the friend-adolescent relationship: Findings from studies of adolescent smoking and drinking. Journal of Applied Social Psychology, 18, 289-314.

Francis, L. J. (1997). The impact of personality and religion on attitude towards substance use among 13-15 year olds. Drug and Alcohol Dependence, 44(2-3), 95-103.

Freeman, R. B. (1986). Who escapes? The relation of churchgoing and other background factors to the socioeconomic performance of black male youths from inner-city tracts. In R. B. Freeman \& H. J. Holzer (Eds.), The black youth employment crisis (pp. 353-376). Chicago: University of Chicago Press.

Gorsuch, R. L., \& McFarland, S. G. (1972). Single vs. multi-item scales for measuring religious values. Journal for the Scientific Study of Religion, 11, 53-63.

Grunbaum, J. A., Kann, L., Kinchen, S. A., Williams, B., Ross, J. G., Lowry, R., \& Kolbe, L. (2002). Youth risk behavior surveillance-United States, 2001. Morbidity and Mortality Weekly Report, 51(SS04), 1-64.

Hadaway, C. K., Elifson, K. W., \& Petersen, D. M. (1984). Religious involvement and drug use among urban adolescents. Journal for the Scientific Study of Religion, 23, 109-128.

Holder, D. W., Durant, R. H., Harris, T. L., Daniel, J. H., Obeidallah, D., \& Goodman, E. (2000). The association between adolescent spirituality and voluntary sexual activity. Journal of Adolescent Health, 26(4), 295-302.

Jensen, L., Newell, R. J., \& Holman, T. (1990). Sexual behavior, church attendance, and permissive beliefs among unmarried young men and women. Journal for the Scientific Study of Religion, 29, 113-117.

Johnson, B. R., Larson, D. B., De Li, S., \& Jang, S. J. (2000). Escaping from the crime of inner cities: Church attendance and religious salience among disadvantaged youth. Justice Quarterly, 17, 377-391.

Johnston, L. D., O’Malley, P. M., \& Bachman, J. G. (2001). National survey results on drug use from the Monitoring the Future study
(Vol. 1: Secondary Students ed.). Rockville, MD: National Institute on Drug Abuse.

Koenig, H. G., McCullough, M. E., \& Larson, D. B. (2001). Handbook of religion and health. New York: Oxford University Press.

Lincoln, C. E., \& Mamiya, L. H. (1990). The black church in the African American experience. Durham, NC: Duke University Press.

Lorch, B. R., \& Hughes, R. H. (1985). Religion and youth substance use. Journal of Religion and Health, 24(3), 197-208.

Mason, W. A., \& Windle, M. (2002). A longitudinal study of the effects of religiosity on adolescent alcohol use and alcoholrelated problems. Journal of Adolescent Research, 17(4), 346363.

Mattis, J. S., \& Jagers, R. J. (2001). A relational framework for the study of religiosity and spirituality in the lives of African Americans. Journal of Community Psychology, 29, 519-539.

Mayer, R. R., Forster, J. L., Murray, D. M., \& Wagenaar, A. C. (1998). Social settings and situations of underage drinking. Journal of Studies on Alcohol, 59(2), 207-215.

Mullen, K., \& Francis, L. J. (1995). Religiosity and attitudes towards drug use among Dutch school children. Journal of Alcohol and Drug Education, 41(1), 16-25.

Myers, L. J. (1993). Understanding an Afrocentric world view : Introduction to an optimal psychology. Dubuque, Ia: Kendall/Hunt.

Petraitis, J., Flay, B. R., \& Miller, T. Q. (1995). Reviewing theories of adolescent substance use: Organizing pieces in the puzzle. Psychological Bulletin, 117, 67-86.

Rosenbaum, E., \& Kandel, D. B. (1990). Early onset of adolescent sexual behavior and drug involvement. Journal of Marriage and the Family, 52, 783-798.

Steinman, K. J., \& Sahr, T. (2002). Ethnic group differences in the relationship between religious participation and substance use among adolescents. Paper presented at the Annual Meeting of the American Public Health Association, Philadelphia, PA.

Studer, M., \& Thornton, A. (1987). Adolescent religiosity and contraceptive usage. Journal of Marriage and the Family, 49, 117128.

Thomas, S. B., Quinn, S. C., Billingsley, A., \& Caldwell, C. H. (1994). The characteristics of northern black churches with community health outreach programs. American Journal of Public Health, $84,575-579$.

Wallace, J. M., Jr., \& Forman, T. A. (1998). Religion's role in promoting health and reducing risk among American youth. Health Education and Behavior, 25(6), 721-741.

Wallace, J. M., \& Williams, D. R. (1997). Religion and adolescent health-compromising behavior. In J. E. Schulenberg, J. L. E. Maggs, \& K. Hurrel-Mann (Eds.), Health risks and developmental transitions during adolescence (pp. 444-468). New York: Cambridge University Press.

Willett, J. B., \& Sayer, A. G. (1994). Using covariance structure analysis to detect correlates and predictors of individual change over time. Psychological Bulletin, 116(2), 363-381.

Winfield, L. F. (1995). The knowledge base on resilience in African American adolescents. In L. J. E. Crockett \& A. C. E. Crouter (Eds.), Pathways through adolescence: Individual development in relation to social contexts (pp. 87-118). Hillsdale, NJ: Erlbaum.

Youniss, J., McLellan, J. A., Su, Y., \& Yates, M. (1999). The role of community service in identity development: Normative, unconventional, and deviant orientations. Journal of Adolescent Research, 14(2), 248-261.

Youniss, J., Yates, M., \& Su, Y. (1997). Social integration: Community service and marijuana use in high school seniors. Journal of Adolescent Research, 12(2), 245-262.

Zimmerman, M. A., \& Maton, K. I. (1992). Life-style and substance use among male African American urban adolescents: A cluster analytic approach. American Journal of Community Psychology, 20(1), 121-138. 